\section{(C) OPEN ACCESS}

\title{
Individualised tobacco affordability in the UK 2002- 2014: findings from the International Tobacco Control Policy Evaluation Project
}

\author{
Timea R Partos, ${ }^{1,2}$ J Robert Branston, ${ }^{3}$ Rosemary Hiscock, ${ }^{2,4}$ Anna B Gilmore, ${ }^{2,4}$ \\ Ann McNeill, ${ }^{1,2}$
}

\begin{abstract}
- Additional material is published online only. To view please visit the journal online (http://dx.doi.org/10.1136/ tobaccocontrol-2017-054027).

${ }^{1}$ Addictions Department, King's College London, London, UK UK Centre for Tobacco \& Alcohol Studies (UKCTAS), Nottingham, UK ${ }^{3}$ School of Management, University of Bath, Bath, UK ${ }^{4}$ Department for Health, University of Bath, Bath, UK
\end{abstract}

Correspondence to Dr Timea R Partos, Addictions Department, King's College London, London SE5 8BB, UK timea.partos@kcl.ac.uk

Received 4 September 2017 Revised 19 May 2018 Accepted 24 May 2018 Published Online First 23 July 2018
Check for updates

To cite: Partos TR,

Branston JR, Hiscock R, et al. Tob Control 2019;28:s9-s19.

\section{ABSTRACT}

Objective The existing measures of tobacco affordability (smokers' purchasing power for tobacco) use national estimates of income and average cigarette prices, and exclude roll-your-own (RYO) tobacco. This study developed an individualised measure of tobacco affordability using smokers' own incomes and factorymade (FM) or RYO tobacco purchase prices, and explored how it was impacted by taxation changes, individual characteristics and purchase patterns.

Design Cross-sectional survey data collated from 10 waves of a longitudinal cohort study.

Data sources Adult smokers $(n=4062)$ from the International Tobacco Control Policy Evaluation Project United Kingdom (UK), surveyed between 2002 and 2014, providing 8943 observations over 10 surveys.

Analysis Affordability was calculated as the percentage of annual income remaining with the individuals after their annual tobacco expenditure. Multilevel linear regression models were used with affordability as the outcome using time, sex, age, geographical region, ethnicity, education, nicotine dependence and tobacco purchase source as the predictor variables.

Results Affordability of FM cigarettes decreased significantly from $91.5 \%$ ( $\pm 95 \% \mathrm{Cl}: 91.0 \%$ to $91.9 \%)$ in 2002 to $87.8 \%(87.0 \%$ to $88.5 \%)$ in 2014 ; and RYO from $96.3 \%$ (95.7\% to $96.9 \%$ ) in 2006 to $93.7 \%$ $(93.0 \%$ to $94.4 \%)$ in 2014 . Affordability was significantly lower for FM than RYO. Year-on-year decreases were not statistically significant. Tobacco was more affordable for males, those with higher education, less dependent smokers and those purchasing from non-store (potentially illicit) or non-UK sources.

Conclusions An individualised measure of tobacco affordability provided useful insights on the impact of tobacco taxes, social inequalities and purchase patterns in the UK. Although tobacco became less affordable, the annual rate of decline was low, suggesting annual tax rises were not large enough.

\section{INTRODUCTION}

Raising cigarette prices through tobacco taxation is one of the most effective and socially equitable tobacco control measures. ${ }^{1-4}$ However, the impact of price rises is modified by inflation rates and changes in incomes..$^{5}$ Therefore, affordability (an indicator of smokers' purchasing power for tobacco with respect to both income and tobacco prices) needs to be understood to measure the impact of tobacco taxes. ${ }^{6}$ More affordable cigarettes lead to increases in consumption. ${ }^{7}$ Several measures of tobacco affordability have been developed to assess affordability. These measures have been standardised to enable affordability to be measured within countries over time, and to allow for between-country comparisons.

Existing tobacco affordability measures include the 'Big Mac index' representing the number of cigarettes purchased for the price of one McDonald's Big Mac hamburger ${ }^{8}$; the 'minutes of labour' (MoL) needed to purchase a pack of 20 Marlboro cigarettes or an equivalent local brand'; the 'relative income price' (RIP) representing the percentage of per capita gross domestic product (GDP) required to purchase 100 packs of cigarettes (Marlboro or local brand $)^{5}$; and the 'cigarette price daily income ratio' (CPDIR), which divides the price of one pack of cigarettes (Marlboro or local brand) by daily income. ${ }^{10}$ These measures have different strengths and weaknesses and their merits, particularly when compared across high-income, middle-income and low-income countries, have been discussed elsewhere. $^{11}$

The main drawback of these 'aggregate' measures is their reliance on average cigarette prices typically derived from only a handful of brands, and on average national estimates of incomes. This can be problematic given the wide income inequalities observed within many countries. To some extent, aggregate measures can capture the range of prices between different factory-made (FM) tobacco brands by using the cheapest local brand as a comparison. ${ }^{5} 7$ However, this still does not fully account for the widening range of difference in prices between different tobacco products (such as FM and roll-your-own (RYO) tobacco) and the numerous strategies smokers can adopt to minimise costs, such as buying in bulk and purchasing from cheaper sources. ${ }^{12} 13$ One study overcame the problem of average prices by using smokers own reported prices for their most recent tobacco purchase; however, their income measure was still based on per capita GDP. ${ }^{14}$ Furthermore, none of the measures of tobacco affordability to date have included RYO tobacco, a much cheaper alternative to FM cigarettes. ${ }^{131516}$ As smoking is concentrated in more disadvantaged groups in countries with a mature smoking epidemic, using individualised income has advantages over per capita GDP as it captures differences in the distribution of income across the smoker population and also enables a more fine-grained analysis of differences in affordability across socioeconomic groups. While some 
studies have used the UBS Survey of Earnings survey to indicate national income as it captures income across several different professional groups, the UBS survey is not designed to be representative of earnings across a country and does not cover unskilled work or unemployed people.

Smokers purchasing cheaper tobacco can weaken the relationship between aggregate affordability measures and tobacco consumption. For example, a study of Thai smokers found no significant change in affordability or overall cigarette consumption despite price rises, yet when examining consumption within separate price tiers, a significant decrease was observed in consumption in the upper and middle tiers, which was offset by an increase of consumption in the lowest tier. ${ }^{17}$ Existing aggregate measures of affordability can also limit their estimates of price to fully taxed sources; however, purchasing from low taxed (eg, duty free, cross-border) or untaxed (illicit) sources can also influence affordability. ${ }^{18-20}$ Examining how individual choices and demographics impact tobacco affordability has seldom been a focus of previous research, but assessing them would enable an individualised measure of affordability, which will be complementary to aggregate measures.

The present study aims to examine tobacco affordability in the United Kingdom between 2002 and 2014, while addressing the gaps in the literature outlined above. The UK levies one of the highest tobacco taxes globally, besides having strong tobacco control policies alongside. ${ }^{21}$ Multicountry comparison studies indicate that although cigarettes in the UK have become less affordable since the 1990s, the rate of decline in affordability might be slowing. Between 1991 and 2002, the annual decrease in MoL tobacco affordability was around $5.5 \%,{ }^{9}$ but only around 2\%-3\% between 2003 and $2009 .^{22}$ Similarly, estimates using the RIP indicated an annual decrease in affordability of around $2.5 \%-3 \%$ between 1990 and $2001,{ }^{5}$ but only 1\%-2\% between 2004 and $2010 .{ }^{6}$ No studies have examined tobacco affordability in the UK since 2010. Yet, since 2010, the UK has also seen a significant widening of the price range between the cheapest and most expensive tobacco products ${ }^{12}{ }^{13}$ and an influx of cheaper tobacco brands. ${ }^{12}$ Economic and policy changes have also occurred during this time. Between 2002 and 2008, UK tobacco taxes increased at the rate of inflation, whereas from 2009 to 2014 , they were typically around $2 \%$ above inflation, with a high of $5 \%$ in $2012 .{ }^{23}$ Furthermore, to comply with the European Commission directive 2010/12/EU, ${ }^{24}$ in 2011, the UK began to use the weighted average price (WAP) instead of the most popular price category (MPPC) to calculate tobacco taxes, and also implemented a large increase in the tax on RYO relative to FM cigarettes. ${ }^{25}$ Starting in 2008 , the UK also experienced an economic recession.

This study will develop an individualised measure of tobacco affordability, based on smokers' own reported incomes and tobacco purchase prices. Unlike previous research, we will also include RYO tobacco in our analyses. In addition to looking at the change in affordability over time, we will explore the impact of individual differences such as demographics, dependence, tobacco format (FM or RYO) and purchase source (taxed versus low or untaxed). The usefulness of the individualised measure is, first, that it is more representative because it will capture what people are actually spending given that they may be buying cheaper brands, or using cheaper sources, rather than an aggregate measure based on a few brands only and national income estimates. Second, it is more meaningful because it calculates the affordability relative to actual incomes. So it paints a better picture to policy-makers and service providers (for example) about the actual magnitude of the financial burden of smoking for different subgroups. Our findings will therefore help to inform future policy decision-making on tobacco pricing in the UK and possibly elsewhere. However, we note that aggregate measures of affordability have a clear implication, such that when affordability of tobacco changes, for example because of a tobacco price increase, the demand for tobacco decreases. Our individualised measure of affordability depends on relative tobacco expenditures, and therefore price increases will not necessarily translate into decreases in demand, and changes in individualised affordability are instead partly a consequence of changes in demand.

\section{METHODS}

\section{Participants}

Participants were from the UK arm of the International Tobacco Control (ITC) Policy Evaluation Project, a cohort survey of adult (aged 18 years or over) smokers with replenishment. Ten surveys took place between 2002 and 2014. Surveys are administered via computer-aided telephone interview or online (from 2008 onwards), with stratified random sampling to be representative of the national distributions of age, sex and geographical region. Detailed information about ITC methodology is published elsewhere. ${ }^{26}{ }^{27}$ We excluded nondaily smokers $(\mathrm{n}=394)$, smokers of both FM cigarettes and RYO tobacco throughout $(n=636)$ and exclusive RYO smokers from the first four surveys $(n=420)$ because some questions needed to calculate affordability were not asked. We also excluded invalid responses on tobacco price $(\mathrm{n}=186$, see below), the top and bottom 1 percentile of responses on the affordability variable to minimise outliers $(n=480$, of which $94 \%$ comprised improbable responses such as spending none or over $100 \%$ of income on tobacco), and anyone with missing data on the included covariates $(\mathrm{n}=58)$. The final sample of 4062 current daily smokers provided 8943 observations over the 10 surveys (average 2.2 observations per individual).

\section{Measures}

Affordability

The individualised affordability measure developed in this study was calculated as the percentage of a smoker's annual gross income remaining after subtracting their annual spend on tobacco (see equation 1), such that higher values represented more affordable tobacco. Values could theoretically range between $0 \%$ and $100 \%$. However, after excluding outliers, affordability in the sample ranged between $35.3 \%$ and $99.9 \%$.

$$
\text { IndividualisedAffordability }=\left(\frac{\text { Income-AnnualTobaccoSpend }}{\text { Income }}\right) \times 100 \%
$$

An aggregate measure of affordability, based on average tobacco prices and national estimates of income, was also calculated for comparison. We adapted the methodology for calculating Blecher and Walbeek's RIP ${ }^{5}$ which is the percentage of per-capita GDP required to purchase 100 packs of $20 \mathrm{FM}$ cigarettes (2000 cigarettes). To make values comparable in magnitude and direction to our measure, we made two adjustments. First, we tripled the number of cigarettes (to 6000 cigarettes or 300 packs of 20) to correspond more closely to the average number of cigarettes smoked per year by our sample, which was 6074 (SD =2913). Second, we inverted the equation so that like our own measure, higher values would indicate more affordable cigarettes. Equation 2 presents the formula for Consumer Price Index (CPI this aggregate affordability measure. UK cigarette prices (FM only) were based on the MPPC from 2002 to 2010 or the WAP from 2011 to 2014, as these are the data published by 
the European Commission ${ }^{28}$ and on which UK tobacco taxes are based. Cigarette prices and yearly GDP figures were adjusted for inflation to 2014 values using the Consumer Price Index (CPI). GDP and CPI data were obtained from the Office of National Statistics (ONS). ${ }^{29} 30$

$$
\text { AggregrateAffordability }=\left(\frac{\text { GDP-TobaccoSpend } \text { G000cigarettes }_{\text {S }}}{\text { GDP }}\right) \times 100 \%
$$

\section{Income}

Gross annual household income was reported in ranges (£0-£6499; £6500-£15000; £15001-£30000; £30001-£40 000; £40001-£50 000; £50001-£65 000; £65001-£95000; or $£ 95001$ and higher). To calculate affordability, we took the mid-point of each range and $£ 95001$ for the highest value. Incomes were adjusted to 2014 values using CPI data. Participants also reported their household composition, which was used to derive 'equivalised' annual income (adjusted for household composition) using the modified Organisation for Economic Co-operation and Development (mOECD) scale. ${ }^{31}$ Equivalisation weights were modified slightly because children's ages in the ITC questionnaire were stratified somewhat differently to the mOECD strata (further details are available from the corresponding author). Due to the complexities and slight deviations from the published methodologies involved in equivalising income, we ran sensitivity analyses using a version of income that was not equivalised for household composition. The results of these analyses did not deviate substantially from the results presented using equivalised income and did not alter the conclusions drawn from the data (data not shown).

\section{Annual tobacco spend}

Participants reported the format of their last tobacco purchase (FM cigarettes by the pack, by the carton or RYO tobacco), including the number of packs, cartons or pouches, and how many packs per carton, cigarettes per pack or grams of tobacco per pouch. The purchase price was also reported. RYO users were also asked how many days a pouch of this weight would usually last, and the number of cigarettes they smoked per day (CPD). This information was used to derive the 'price per stick' separately for FM and RYO users.

These calculations for price per stick were adapted from a previous study using this dataset, ${ }^{13}$ and the same exclusion criteria for improbable responses were adopted here. Annual tobacco spend was then calculated by multiplying the price per stick by CPD and by 365 . We felt it reasonable to extrapolate annual expenditure from participants' most recent purchase, as the large majority of our sample $(92.2 \%$ of FM and $95.4 \%$ of RYO users) indicated their most recent purchase to be their usual brand.

\section{Time (tobacco tax year)}

Each ITC survey period spanned a number of months. We assigned participants to the appropriate 'tobacco tax year' corresponding to the timing of their response relative to when tobacco tax changes were implemented (March or April each year). No ITC survey data were collected in the 2009 or 2011 tobacco tax years.

\section{Demographics}

Demographic variables were sex, age, UK geographical region of residence, ethnicity (white or non-white) and highest level of education attained (low $=$ secondary school/vocationallevel 3 or less; moderate $=$ somecollege or university but no degree and high $=$ completed university or postgraduate degree). Importantly, level of education served as an indicator of socioeconomic differences, as we could not include income as a covariate because it was used to derive the affordability measure itself.

\section{Nicotine dependence}

The time to first cigarette (TTFC) after waking was used to indicate dependence, stratified to within 5 min (most dependent); 6 to $30 \mathrm{~min}$; 31 to $60 \mathrm{~min}$; and after $60 \mathrm{~min}$ (least dependent).

\section{Purchase source}

We classified the reported source of participants' last tobacco purchase into two categories using criteria detailed elsewhere. ${ }^{13}$

1. UK store-based sources (eg, supermarkets, pubs, tobacconists) represented easily accessible and widely used sources that were highly likely to be legal sales. 2. Non-UK/non-store sources (eg, duty free, informal sellers, friends) represented a concerted effort to obtain cheap (potentially including illicit) tobacco.

\section{Analyses}

A basic descriptive comparison of individualised and aggregate affordability was achieved by calculating the changes over time for both the measures. We also computed the changes over time of the constituents of affordability (income and tobacco price) to examine their relative contributions.

To investigate changes in individualised affordability over time, and the associations with individual differences we used multilevel linear random effects regression analyses with maximum likelihood estimation, clustered over individuals. The clustering controlled for correlations between multiple observations provided by the same individual at different surveys. Affordability of FM cigarettes (2002-2014) was analysed separately from RYO tobacco (2006-2014). The dependent variable was our individualised measure of affordability. The independent variables were tobacco tax year (we used the 2002 tobacco tax year as reference, and tested for linear trends, and also conducted reverse adjacent contrasts, which indicated whether each successive period from one survey to the next resulted in a change in affordability that was statistically significant), sex, age and age squared (to test for nonlinear associations with age), geographical region, ethnicity, education, TTFC and purchase source. A random-effect rather than fixed-effect regression model was chosen because of the emphasis on population-level effects rather than cluster-level effects of random effects modelling, its ability to handle small clusters and clusters of one such as was present in our sample, and the ability to model the effects of time-invariant variables such as sex and ethnicity on the outcome. It should also be noted that we recognise the importance of tax changes to affordability. Unfortunately, however, tax changes completely overlapped with the time variable in our dataset and was therefore a confound that could not be included in our regression model.

Three regression models were computed. Model 1 regressed affordability separately on each independent variable, unadjusted for any other covariates. These univariate analyses indicated if there were any simple associations between each of our independent variables and affordability. Model 2 was fully adjusted for all independent variables concurrently. This indicated which of our independent variables made a significant contribution to predicting affordability, even after controlling for all other included variables. Model 3 repeated model 2 but excluded participants purchasing from non-UK/non-store sources to observe changes in affordability only among sources 
where full duties were likely to have been paid. Note that neither income nor CPD were included as covariates as these variables were used to derive the affordability measure itself.

A sensitivity analysis was also conducted to examine how smokers changed their tobacco consumption (CPD) over the survey period. This assessed whether any observed changes in affordability were due to changes in tobacco consumption. This analysis regressed CPD onto all the independent variables included in model 2.

\section{RESULTS}

Sample characteristics are presented in table 1 . The majority were white, had low to moderate education, smoked their first cigarette within $30 \mathrm{~min}$ of waking and purchased tobacco predominantly from UK store-based sources. The mean age was 48 years $(S D=14)$, and there were slightly more females $(58 \%)$ than males. The majority of FM smokers were female (62\%), whereas the majority of RYO smokers were male (63\%). Although there were some differences in geographical region of residence, the FM and RYO groups were comparable in age, level of education and TTFC. Consistent with previous research, ${ }^{13}{ }^{19} \mathrm{RYO}$ smokers were somewhat more likely to purchase tobacco from non-UK/ non-store sources.

\section{Affordability over time}

An average annual increase in prices of $2.6 \%$ for FM cigarettes and $4.5 \%$ for RYO tobacco, and an average annual decrease of $1.6 \%$ in incomes (figure 1A) both contributed to a small decrease in individualised affordability (figure 1B) over the survey period. The income of the smokers in our sample deviated considerably from the national annual per capita GDP. Between 2002 and 2007, GDP increased from $£ 26206$ to $£ 30299$, whereas income for our sample decreased from $£ 32202$ to $£ 29423$, and continued to decrease at a more marked rate than GDP to a low of $£ 24976$ in 2012 (GDP reached a low of $£ 27196$ ), after which both indicators saw a modest increase (see also the online supplementary figure S1). The affordability of FM cigarettes decreased at an average annual rate of $0.24 \%$, from $91.5 \%$ ( $\pm 95 \%$ CI: $91.0 \%$ to $91.9 \%$ ) in 2002 to $87.8 \%$ ( $\pm 95 \%$ CI: $87.0 \%$ to $88.5 \%$ ) in 2014. The affordability of RYO tobacco decreased at an average annual rate of $0.31 \%$, from $96.3 \%$ ( $\pm 95 \%$ CI: $95.7 \%$ to $96.9 \%)$ in 2006 to $93.7 \%$ ( $\pm 95 \%$ CI: $93.0 \%$ to $94.4 \%$ ) in 2014 . Affordability was significantly lower for FM cigarettes than RYO tobacco. These figures are unadjusted for any covariates and inclusive of all purchase sources (model 1). Aggregate affordability (fully taxed FM cigarettes only) also decreased. The spike that was evident between 2010 and 2011 coincides with the period during which the calculation of cigarette prices changed from the MPPC to the WAP, marking the switch between these two data series. Aggregate affordability decreased at an average annual rate of $0.13 \%$ between 2002 (93.4\%) and 2010 (92.5\%) when MPPC was used, and at an average annual rate of $0.40 \%$ between 2011 (93.7\%) and 2014 (92.5\%) when the WAP was used.

For FM cigarettes (table 2), the unadjusted regression (model 1) indicated a significant linear trend, $\chi^{2}(1)=118.8, p<0.0001$, in the decrease in individualised affordability over time. Reverse adjacent contrasts, however, indicated that none of the year-onyear decreases were significant, with the exception of the two instances where there was a two-year interval between surveys, in 2008-2010, $\chi^{2}(1)=8.9, p<0.005$, and $2010-2012, \chi^{2}(1)=4.0$, $\mathrm{p}<0.05$. The same pattern of results was obtained for the fully adjusted model 2. When we excluded purchases made from
Table 1 Sample characteristics for the combined sample, and separately by tobacco format: factory made (FM) cigarettes or rollyour-own (RYO) tobacco

\begin{tabular}{|c|c|c|c|c|c|c|}
\hline & \multicolumn{2}{|c|}{$\begin{array}{l}\text { Combined } \\
\text { sample }\end{array}$} & \multicolumn{2}{|c|}{ FM smokers } & \multicolumn{2}{|c|}{ RYO smokers } \\
\hline & obs & $\%$ & obs & $\%$ & obs & $\%$ \\
\hline Total observations & 8943 & 100.0 & 7475 & 100.0 & 1468 & 100.00 \\
\hline \multicolumn{7}{|l|}{$\begin{array}{l}\text { Individualised } \\
\text { Affordability (\%) }\end{array}$} \\
\hline Mean and SD & 91.4 & 9.7 & 90.6 & 10.1 & 95.5 & 5.9 \\
\hline \multicolumn{7}{|l|}{ Annual Income (f) } \\
\hline Mean and SD & 29347 & 21832 & 30277 & 22464 & 24608 & 17534 \\
\hline \multicolumn{7}{|l|}{ Price per cigarette (f) } \\
\hline Mean and SD & 0.265 & 0.080 & 0.273 & 0.075 & 0.227 & 0.092 \\
\hline \multicolumn{7}{|l|}{ Cigarettes per day } \\
\hline Mean and SD & 16.8 & 8.2 & 16.7 & 8.1 & 17.0 & 9.1 \\
\hline \multicolumn{7}{|l|}{ Sex $(\%)$} \\
\hline Female & 5196 & 58.1 & 4647 & 62.2 & 549 & 37.4 \\
\hline Male & 3747 & 41.9 & 2828 & 37.8 & 919 & 62.6 \\
\hline \multicolumn{7}{|l|}{ Age } \\
\hline Mean and SD & 49 & 14.2 & 48 & 14.4 & 50 & 12.9 \\
\hline \multicolumn{7}{|l|}{ Region } \\
\hline London & 1094 & 12.2 & 964 & 12.9 & 130 & 8.9 \\
\hline $\begin{array}{l}\text { Yorkshire and The } \\
\text { Humber }\end{array}$ & 729 & 8.2 & 645 & 8.6 & 84 & 5.7 \\
\hline East Midlands & 634 & 7.1 & 513 & 6.9 & 121 & 8.2 \\
\hline Eastern & 753 & 8.4 & 601 & 8.0 & 152 & 10.4 \\
\hline North East & 393 & 4.4 & 340 & 4.6 & 53 & 3.6 \\
\hline South East & 1139 & 12.7 & 930 & 12.4 & 209 & 14.2 \\
\hline South West & 657 & 7.6 & 478 & 6.4 & 197 & 13.4 \\
\hline West Midlands & 797 & 8.9 & 679 & 9.1 & 118 & 8.0 \\
\hline North West & 951 & 10.6 & 819 & 11.0 & 132 & 9.0 \\
\hline Wales & 479 & 5.4 & 368 & 4.9 & 111 & 7.6 \\
\hline Scotland & 1009 & 11.3 & 882 & 11.8 & 127 & 8.7 \\
\hline Northern Ireland & 290 & 3.2 & 256 & 3.4 & 34 & 2.3 \\
\hline \multicolumn{7}{|l|}{ Ethnicity } \\
\hline White & 8534 & 95.4 & 7094 & 94.9 & 1440 & 98.1 \\
\hline Not white & 409 & 4.6 & 381 & 5.1 & 28 & 1.9 \\
\hline \multicolumn{7}{|l|}{ Education } \\
\hline Low & 5236 & 58.6 & 4389 & 58.7 & 847 & 57.7 \\
\hline Moderate & 2380 & 26.6 & 1998 & 26.7 & 382 & 26.0 \\
\hline High & 1327 & 14.8 & 1088 & 14.6 & 239 & 16.3 \\
\hline \multicolumn{7}{|l|}{$\begin{array}{l}\text { Time to first cigarette } \\
\text { (TTFC) }\end{array}$} \\
\hline $\begin{array}{l}\text { Least addicted (over } \\
60 \mathrm{~min} \text { ) }\end{array}$ & 1218 & 13.6 & 1066 & 14.3 & 152 & 10.4 \\
\hline $31-60 \mathrm{~min}$ & 1879 & 21.0 & 1593 & 21.3 & 286 & 19.5 \\
\hline $6-30 \min$ & 4407 & 49.3 & 3667 & 49.1 & 740 & 50.4 \\
\hline $\begin{array}{l}\text { Most addicted } \\
\text { (within } 5 \mathrm{~min} \text { ) }\end{array}$ & 1439 & 16.1 & 1149 & 15.4 & 290 & 19.8 \\
\hline \multicolumn{7}{|l|}{ Purchase source } \\
\hline UK store-based & 7495 & 83.8 & 6439 & 86.1 & 1056 & 71.9 \\
\hline Non-UK/non-store & 1448 & 16.2 & 1036 & 13.9 & 412 & 28.1 \\
\hline
\end{tabular}

Total $n=4062$, observations $=8943$.

non-UK/non-store sources (model 3), there was still a significant linear decrease in affordability with time, $\chi^{2}(1)=54.3, \mathrm{p}<0.0001$. Adjacent contrasts, however, showed that none of the year-on-year decreases remained statistically significant. Model 3 for FM cigarettes is the most comparable to the aggregate affordability measure 

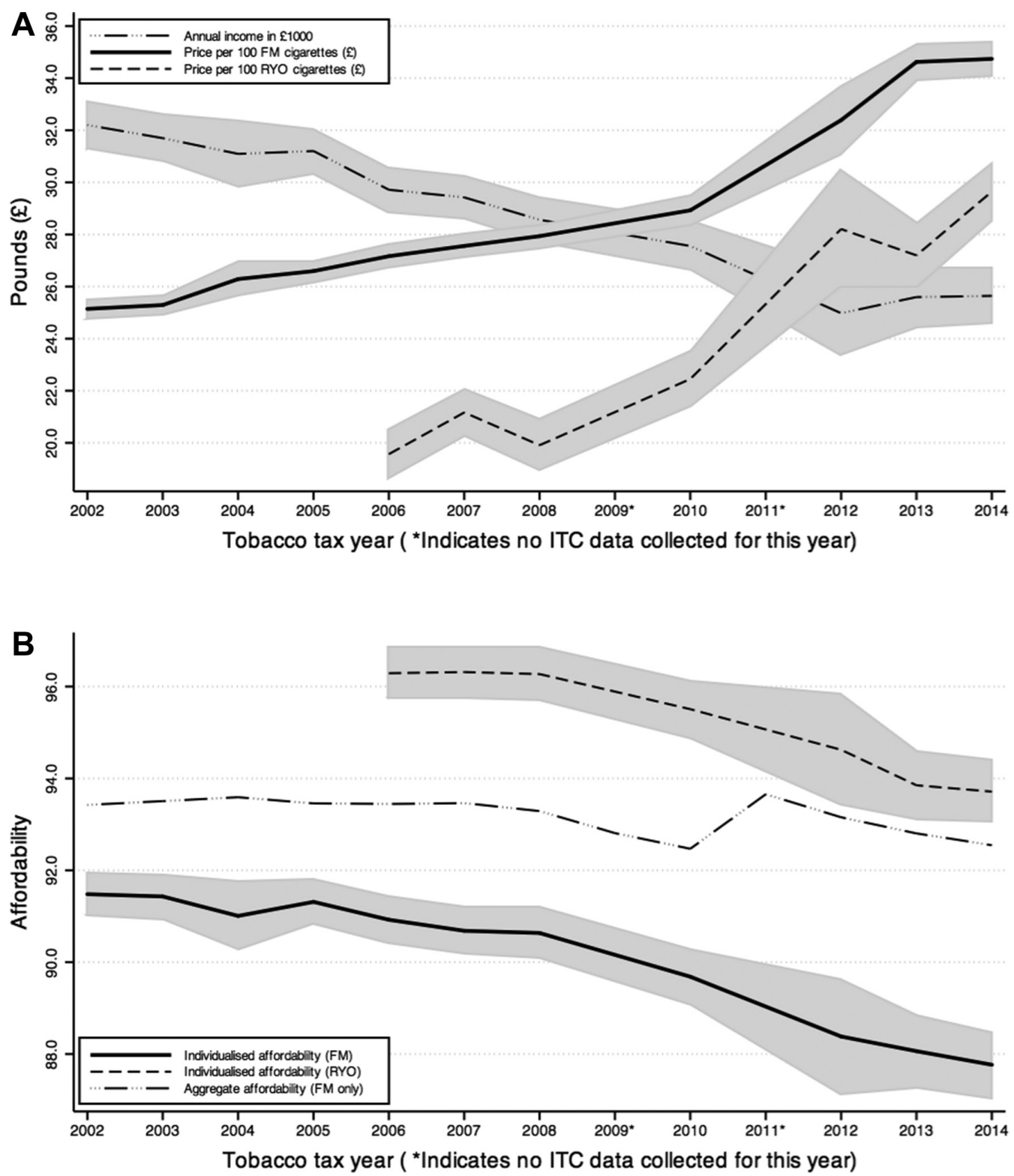

Figure 1 Measures of affordability, and their constituent components, over time, with shaded areas indicating 95\% Cls. (A) indicates annual gross income (in $\mathrm{f1000}$ ) and tobacco prices (per 100 cigarettes, in $\mathrm{f}$ ) separately for factory made (FM) cigarettes and roll-your-own (RYO) tobacco. Values are adjusted for inflation using the consumer price index, with 2014 as the base year. (B) shows the individualised measures of affordability over time for FM cigarettes and RYO tobacco, and for the aggregate affordability measure (FM cigarettes only). Individualised affordability is unadjusted and inclusive of all sources (model 1, see text for details). Aggregate affordability is based on annual per capita gross domestic product and mean cigarette prices from annual sales in the most popular price category (prior to 2011) or the weighted average price (2011 onwards) for fully taxed UK sources only. ITC, International Tobacco Control.

(inclusive only of FM cigarettes from fully taxed UK sources). Individualised affordability in model 3 was around 3\%-6\% lower than aggregate affordability each year, with a more marked decline. In both models 2 and 3 (adjusted for all covariates), 2010 was the first year that FM cigarettes became significantly less affordable than they had been in 2002. Changes in individualised affordability over time for RYO tobacco (Table 3) were similar to FM cigarettes. The unadjusted analysis (Model 1) indicated a significant linear trend, $\chi^{2}(1)=69.9, p<.0001$, in the decrease of affordability over time, but only the decrease from 2008 to $2010, \chi^{2}(1)=5.3, p<.05$, was statistically significant in the reverse adjacent contrasts. The fully adjusted Model 2 also indicated a significant linear decrease over time, but no significant year-to-year changes. The same pattern was observed when purchases from non-UK/ non-store sources were excluded (Model 3).

\section{Individual differences in affordability}

Unadjusted regressions (model 1) indicated that FM cigarettes were significantly less affordable for females, smokers from the North East and western regions of England, Scotland and Northern Ireland (compared with London), white smokers, those with the lowest level of education, more dependent smokers and those who purchased cigarettes from UK storebased sources (table 2). There was also a significant inverse quadratic association between affordability and age, such that smoking was most affordable for smokers aged around 36 years, 
Table 2 Linear random effects regression analyses of affordability regressed on time (tax year) and other covariates, for factory-made (FM) cigarette smokers only

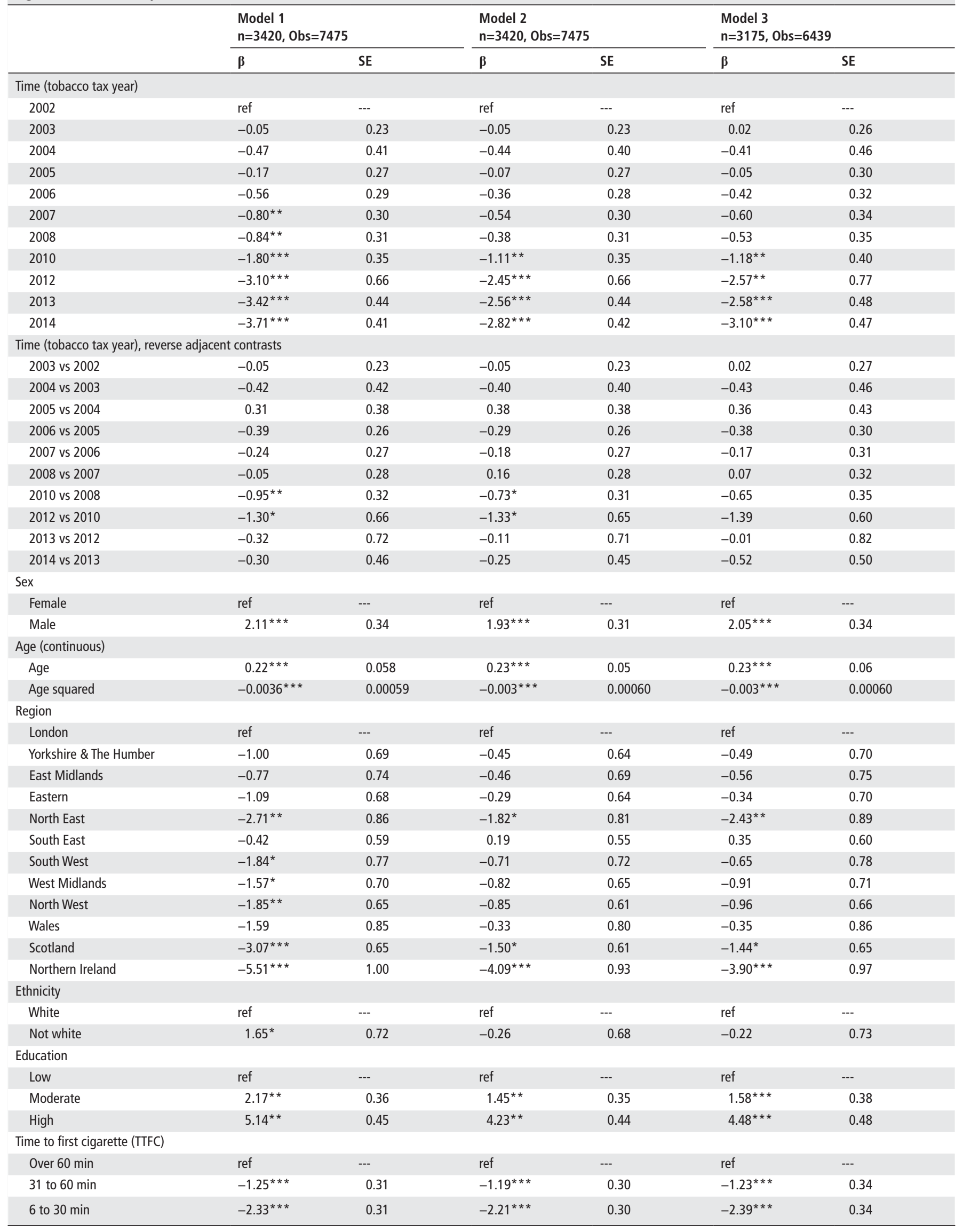


Table 2 Continued

\begin{tabular}{|c|c|c|c|c|c|c|}
\hline & \multicolumn{2}{|c|}{$\begin{array}{l}\text { Model } 1 \\
\mathrm{n}=3420, \text { Obs }=7475\end{array}$} & \multicolumn{2}{|c|}{$\begin{array}{l}\text { Model } 2 \\
n=3420, \text { Obs }=7475\end{array}$} & \multicolumn{2}{|c|}{$\begin{array}{l}\text { Model } 3 \\
n=3175, \text { Obs }=6439\end{array}$} \\
\hline & $\boldsymbol{\beta}$ & SE & $\beta$ & SE & $\beta$ & SE \\
\hline Within 5 min & $-3.87^{* * *}$ & 0.38 & $-3.83^{* * *}$ & 0.37 & $-4.33 * * *$ & 0.41 \\
\hline \multicolumn{7}{|l|}{ Purchase source } \\
\hline UK store-based & ref & --- & ref & --- & --- & --- \\
\hline Non-UK/non-store & $4.15^{* * *}$ & 0.25 & $4.10 * * *$ & 0.25 & --- & --- \\
\hline
\end{tabular}

Note: model 1 is the unadjusted effects, of affordability regressed separately on each predictor variable, model 2 is adjusted for all covariates and model 3 is adjusted for all covariates but excluding purchases from non-UK/non-store sources. (table 3 )

${ }^{*} \mathrm{P}<0.05 ;{ }^{* *} \mathrm{P}<0.01 ;{ }^{* *} \mathrm{P}<0.001$

somewhat less affordable for younger smokers and much less affordable for the oldest smokers. Only minor changes were observed to this pattern of associations in the fully adjusted model 2 (western regions of England no longer differed significantly from London, and differences by ethnicity were no longer significant), and no further changes were observed when we excluded purchases from non-UK/non-store sources in model 3. figure 2 presents individualised affordability of FM cigarettes over time for different demographic groups, where it is evident that large savings can be made by purchasing from non-UK/ nonstore sources, and that the most dependent smokers are spending relatively more of their income on tobacco.

For RYO smokers (table 3), the unadjusted model 1 indicated significantly less affordable tobacco for those with the lowest level of education, those who smoked their first cigarette within $5 \mathrm{~min}$ of waking (versus after $60 \mathrm{~min}$ ) and smokers who purchased from UK store-based sources. In the fully adjusted model 2, the inverse quadratic association between age and affordability that was observed for FM cigarettes became statistically significant, and RYO tobacco was also significantly less affordable for smokers from Wales (versus London). This pattern of associations persisted when we excluded purchases from non-UK/non-store sources in model 3, with the exception that the association with age again became non-significant.

\section{Sensitivity analysis with tobacco consumption (CPD) as the outcome}

The sensitivity analysis indicated a small but significant reduction in cigarette consumption (CPD) over time among FM smokers, from 17.5 (95\% CI: 17.2 to 17.9 ) in 2002 to 16.1 (95\% CI: 15.6 to 16.7$)$ in 2014 , with a significant linear trend $\chi^{2}(1)=40.9$, $P<.0001$. No significant change in CPD over time was observed for RYO smokers, from 16.8 (95\% CI: 16.0 to 17.6) in 2006 to 17.3 (95\% CI: 16.4 to 18.3 ) in 2014, and the linear trend was not statistically significant $\chi^{2}(1)=1.7, P=.20$. The observed decreases in affordability were thus not attributable to changes in cigarette consumption.

\section{DISCUSSION}

Our new individualised measure of affordability indicated that tobacco in the UK was significantly less affordable in 2014 than it had been in 2002. Smokers of FM cigarettes retained $91.5 \%$ of their income after paying for tobacco in 2002, but only $87.8 \%$ in 2014. For the first time, we have been able to assess affordability for RYO smokers and we found that tobacco was more affordable for RYO smokers, but this too decreased significantly, from $96.3 \%$ in 2006 to $93.7 \%$ in 2014 . The decrease was not attributable to changes in cigarette consumption, but to decreases in

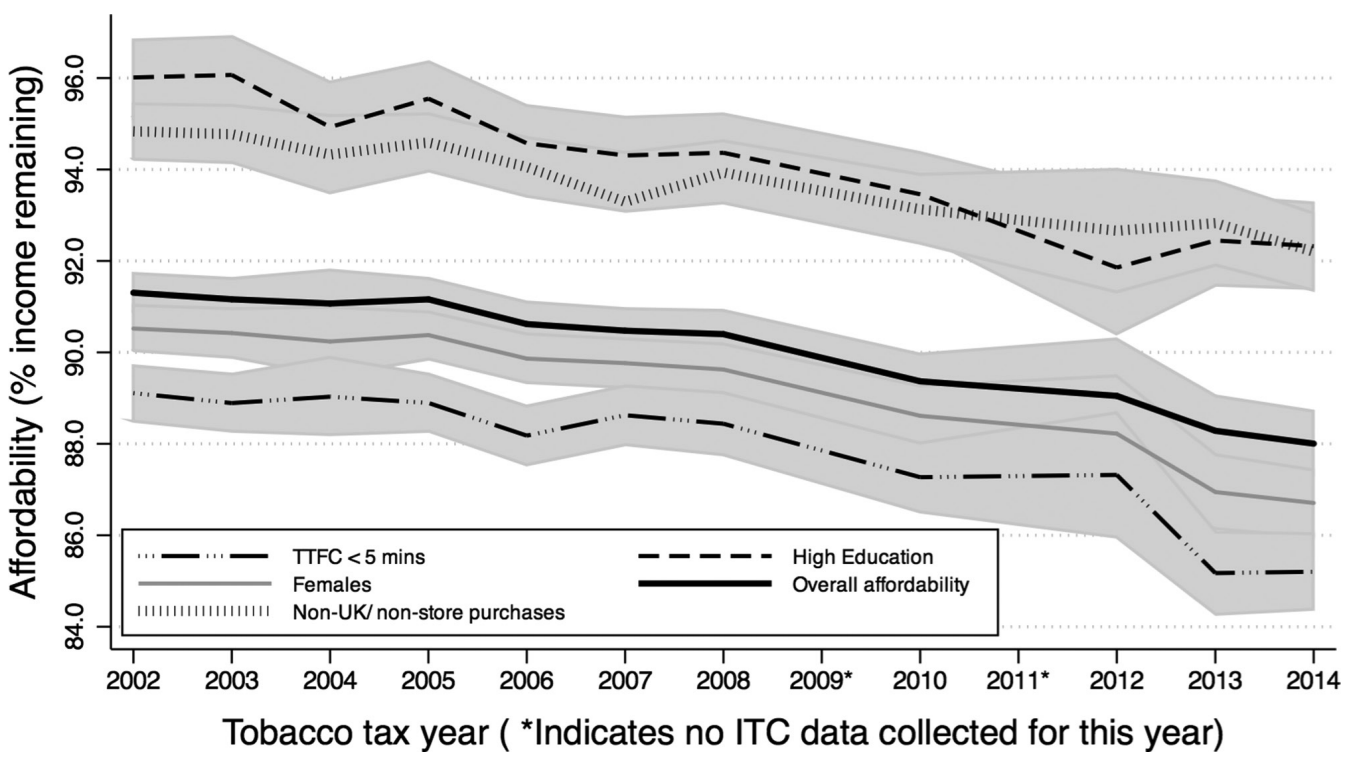

Figure 2 Individualised affordability for female smokers, those with high education, those who smoke their first cigarette within 5 min of waking (TTFC < $5 \mathrm{~min}$ ), and those purchasing from non-UK/nonstore sources, compared with overall affordability. Shaded areas represent $95 \% \mathrm{Cl}$. Affordability estimates are from the fully adjusted model 2 for FM smokers only, and adjusted for covariates (see text for details). FM, factory-made; ITC, International Tobacco Control; TTFC, time to first cigarette. 
Table 3 Linear random effects regression analyses of affordability regressed on time (tax year) and other covariates, for roll-your-own (RYO) tobacco smokers only

\begin{tabular}{|c|c|c|c|c|c|c|}
\hline & \multicolumn{2}{|c|}{$\begin{array}{l}\text { Model } 1 \\
n=734, \text { Obs=1468 }\end{array}$} & \multicolumn{2}{|c|}{$\begin{array}{l}\text { Model } 2 \\
n=734, \text { Obs }=1468\end{array}$} & \multicolumn{2}{|c|}{$\begin{array}{l}\text { Model } 3 \\
\mathrm{n}=598, \text { Obs }=1056\end{array}$} \\
\hline & $\beta$ & SE & $\beta$ & SE & $\beta$ & SE \\
\hline 2006 & ref & --- & ref & --- & ref & --- \\
\hline 2007 & 0.02 & 0.31 & 0.26 & 0.30 & 0.32 & 0.42 \\
\hline 2008 & -0.02 & 0.33 & 0.18 & 0.32 & 0.20 & 0.45 \\
\hline 2013 & $-2.44^{* * *}$ & 0.42 & $-1.94^{* * *}$ & 0.41 & $-2.37^{* * *}$ & 0.53 \\
\hline 2014 & $-2.58^{* * *}$ & 0.40 & $-1.80^{* * *}$ & 0.40 & $-2.16^{* * *}$ & 0.51 \\
\hline \multicolumn{7}{|c|}{ Time (tax year), reverse adjacent contrasts } \\
\hline 2007 vs 2006 & 0.02 & 0.31 & 0.26 & 0.30 & 0.32 & 0.42 \\
\hline 2008 vs 2007 & -0.04 & 0.32 & -0.08 & 0.31 & -0.12 & 0.42 \\
\hline \multicolumn{7}{|l|}{ Sex } \\
\hline Female & ref & --- & ref & --- & ref & --- \\
\hline Male & 0.64 & 0.41 & $0.90^{*}$ & 0.39 & $0.98^{*}$ & 0.48 \\
\hline \multicolumn{7}{|l|}{ Age (continuous) } \\
\hline Age & 0.16 & 0.087 & $0.16^{*}$ & 0.08 & 0.14 & 0.10 \\
\hline Age squared & $-0.0024^{* *}$ & 0.00088 & $-0.002^{* *}$ & 0.00 & $-0.002^{*}$ & 0.00 \\
\hline \multicolumn{7}{|l|}{ Region } \\
\hline London & ref & --- & ref & --- & ref & --- \\
\hline Yorkshire \& The Humber & -0.87 & 1.02 & -0.84 & 0.97 & -0.98 & 1.18 \\
\hline East Midlands & -0.38 & 0.92 & -0.64 & 0.88 & -0.88 & 1.08 \\
\hline Scotland & -0.44 & 0.96 & 0.18 & 0.92 & 0.22 & 1.10 \\
\hline Northern Ireland & -1.15 & 1.39 & -0.38 & 1.32 & -0.02 & 1.49 \\
\hline \multicolumn{7}{|l|}{ Ethnicity } \\
\hline White & ref & --- & ref & --- & ref & --- \\
\hline Not white & -0.89 & 1.19 & -0.08 & 1.13 & -0.22 & 1.30 \\
\hline \multicolumn{7}{|l|}{ Education } \\
\hline Low & ref & -- & ref & --- & ref & --- \\
\hline Moderate & $1.60^{* * *}$ & 0.45 & $1.49 * * *$ & 0.43 & $1.98^{* * *}$ & 0.52 \\
\hline High & $2.01^{* * *}$ & 0.55 & $1.75^{* *}$ & 0.54 & $2.26^{* *}$ & 0.66 \\
\hline \multicolumn{7}{|l|}{ Time to first cigarette (TTFC) } \\
\hline Over $60 \mathrm{~min}$ & ref & --- & ref & --- & ref & --- \\
\hline 31 to 60 mins & 0.03 & 0.51 & -0.05 & 0.48 & -0.18 & 0.62 \\
\hline 6 to $30 \mathrm{~min}$ & -0.81 & 0.49 & $-1.10^{*}$ & 0.40 & $-1.42^{*}$ & 0.60 \\
\hline Within 5 min & $-1.68^{* *}$ & 0.56 & $-2.00 * * *$ & 0.53 & $-2.79 * * *$ & 0.69 \\
\hline \multicolumn{7}{|l|}{ Purchase source } \\
\hline UK store-based & ref & -- & ref & -- & -- & --- \\
\hline Non-UK/non-store & $2.50^{* * *}$ & 0.31 & $2.35^{* * *}$ & & -- & --- \\
\hline
\end{tabular}

Note: model 1 is the unadjusted effects of affordability regressed separately on each predictor variable, model 2 is adjusted for all covariates and model 3 is adjusted for all covariates but excluding purchases from non-UK/nonstore sources.

${ }^{*} \mathrm{P}<0.05 ;{ }^{* *} \mathrm{P}<0.01 ;{ }^{* * *} \mathrm{P}<0.001$ 
income of our sample (1.6\% annually) and increases in mean cigarette prices $(2.6 \%$ and $4.5 \%$ annually for FM and RYO, respectively), both contributing to the decrease in affordability. Our analyses highlighted an advantage of our new individualised measure of affordability, in that it is able to capture income endogeneity. The average incomes of our sample of smokers deviated considerably from national averages based on annual per capita GDP. As smoking is increasingly becoming associated with widening socioeconomic disparities, this is particularly important, and affordability measures using estimates of income based on national averages are less able to capture these shifts.

The decrease in affordability, however, was much lower $(0.24 \%$ and $0.31 \%$ annually for FM and RYO, respectively) than what would be expected from the observed changes in income and cigarette prices. This suggests that individual characteristics play a role. Indeed, tobacco was least affordable for female smokers, older smokers, those with low levels of education and more highly dependent smokers. It also indicates that smokers are able to manage tobacco affordability through their purchase patterns. Smoking RYO tobacco instead of FM cigarettes saved up to $5 \%$ of smokers' annual incomes (around $£ 1300$ in 2014). Purchasing from overseas, duty free or informal/ illicit sources also conferred a saving of around 5\%.

Despite the overall decrease in affordability between 2002 and 2014, the year-on-year changes were not statistically significant (except when there were two-year instead of one-year gaps between surveys) and thus probably not substantial enough to prompt smokers, especially more dependent smokers, to quit. The period between 2008 and 2012 saw the sharpest rate of decrease in affordability (see figure 1B). It was only from 2009 that UK tobacco taxes were greater than the rate of inflation during the study period, ${ }^{23}$ and an especially large increase in RYO tobacco taxes occurred in $2011,{ }^{25}$ when the sharpest increase in RYO prices was observed (figure 1A). This finding clearly underscores the importance of large tax increases that result in tobacco price increases greater than the rate of inflation and for measures that differentially increase RYO taxes in order to reduce the price gap between FM and RYO tobacco products. Indeed, it was only from 2010 onwards that FM cigarettes became significantly less affordable than they had been in 2002. The sharpest drop in incomes for our sample also occurred from 2010 onwards, likely a result of the 2008-09 economic recession. Unfortunately, due to the overlapping timeframes of these changes and gaps in our data collection (no surveys in 2009 or 2011), we cannot conclusively determine the strength of their relative contributions to the changes in affordability. Nevertheless, our findings support the need for large tax increases above the rate of inflation and taxing all tobacco products in a way that minimises the incentive to substitute with cheaper products.

A steady decline in incomes was observed among our sample from 2002 to 2012, yet the wealth of the UK population as a whole was increasing prior to the recession in $2008 .{ }^{30}$ This supports the theory that smoking is increasingly becoming a hallmark of socioeconomic disadvantage. ${ }^{2} 3233$ Indeed, some of the observed individual differences in affordability, such as lower affordability for females, very old smokers, those of low education and regional variations, can plausibly be attributed to lower incomes among these groups. The most dependent smokers are spending about 2\% (RYO) to 4\% (FM) more of their incomes (around $£ 500$ to $£ 1000$ annually in 2014) on tobacco than the least dependent. Providing additional support to these smokers, for whom it is hardest to quit, ${ }^{32} 34$ must remain a priority for policy-makers. In addition, policy-makers should ensure that taxes are applied differentially according to risk: for example, less harmful nicotine products such as nicotine replacement therapies and electronic cigarettes should be taxed at levels commensurate with their relative risks comparable to smoking. ${ }^{35}$

We compared our individualised affordability measure to an aggregate version based on average cigarette prices and national estimates of income. The aggregate measure gave estimates of affordability for FM cigarettes that were about 3\%-6\% higher each year than our individualised measure, and the decline over time was also less marked for aggregate affordability. We believe that our individualised measure offers some benefits over and above the aggregate measure, like the measures of tobacco affordability that are currently in use. ${ }^{5-10}$ These are that it takes individual variations in consumption into account, considers untaxed or illicit purchase sources and the use of RYO tobacco. It is therefore likely that our individualised measure more accurately reflects actual changes in tobacco affordability over time than do aggregate measures, and where feasible, can provide a complementary measure to the extant aggregate affordability measures.

\section{Limitations}

Our sample only included current smokers. Some recent ex-smokers may have quit due to their low levels of tobacco affordability. If this were the case, our data would somewhat underestimate the decrease in affordability. Future research using our individualised measure can explore this by comparing affordability among recent quitters to continuing smokers. Due to insufficient data, nondaily smokers and those who habitually smoked both FM cigarettes and RYO tobacco were also excluded. This may have slightly underestimated affordability, as these groups might be particularly adept at controlling their tobacco expenditure, smoking less or switching between FM and $\mathrm{RYO}$ as needed. Our analysis used repeat cross-sectional data; future studies could assess within subject changes in the individualised affordability measure over time. Future research in this way would also help establish whether differential quitting across different socioeconomic groups is contributing to the decreases in income observed overall in our sample of smokers. Lastly, we only had data on gross (before tax) rather than net (after tax) income. Individuals in the UK with higher incomes are taxed at progressively higher rates, so their net income (what is actually available to spend on tobacco) will be reduced by relatively more than those on lower incomes. For the high-income groups, affordability will therefore be slightly overestimated. However, we do not expect this to cause a large bias in our estimates, as the majority of our sample (68\%) had gross incomes below $£ 30$ 000, which was below the threshold for moving beyond the lowest tax rate in all the years analysed, with the exception of the 2002-2003 tax year where the threshold was $£ 29000 .{ }^{36}$ Future studies, however, might improve on our methodology by using net instead of gross income to calculate affordability. Our measure of affordability relied on high-quality ITC data, and the growing number of countries participating in the ITC increase its applicability.

\section{CONCLUSIONS}

The newly developed individualised measure of tobacco affordability complements aggregate measures based on national estimates of income and average tobacco prices by providing a more accurate and nuanced insight into the impact of tobacco taxes. Tobacco in the UK was significantly less affordable in 2014 than in 2002, although the rate of decrease was low ( $0.24 \%$ annually) 
and year-on-year declines were not significant. Affordability was modified by larger tax increases, in addition to social inequalities and purchase patterns. More dependent smokers and those of low socioeconomic status spent relatively more of their incomes on tobacco. RYO tobacco was considerably more affordable than FM cigarettes, and policy-makers need to focus on closing this gap.

\section{What this paper adds}

\section{What is already known on this subject}

- Raising cigarette prices through tobacco taxation is an effective tobacco control measure, but it is impacted by inflation rates and changes in income. Affordability measures have been developed to enable these considerations to be taken into account and such measures have been standardised to enable comparisons over time and across countries. Extant measures use national income estimates and average cigarette prices of Marlboro or local brands.

What important gaps in knowledge exist on this topic

- Aggregate affordability measures can be problematic given wide income inequalities and the range of prices across brands and different types of tobacco (such as factory made (FM) and roll-your-own (RYO). In addition they cannot account for smokers 'strategies to minimise costs, such as buying in bulk or from cheaper sources.

\section{What this paper adds}

- This study developed a complementary individualised measure of tobacco affordability using smokers' own incomes and FM and (for the first time) RYO tobacco purchase prices. Both FM and RYO became less affordable over time, but RYO was significantly more affordable than FM and the annual rate of decline in individualised affordability was low, suggesting annual tax rises were not large enough. Individual characteristics and purchasing decisions influenced tobacco affordability.

Acknowledgements The authors would like to thank Professor Frank Chaloupka for his support and advice on this manuscript, and the members of the Data Management Core at the University of Waterloo for assistance in preparing the data for this analysis.

Contributors All authors contributed to developing the research question and design of the study. TRP conducted the statistical analyses and first draft of the manuscript. AM, JRB, RH and ABG made substantial contributions to the introduction and the interpretation and discussion of the results.

Funding The ITC UK Project was supported by grants from the US National Cancer Institute (R01 CA100362, R01 P50 CA111236 (Roswell Park Transdisciplinary Tobacco Use Research Center), and P01 CA138389), the Canadian Institutes of Health Research (MOP-57897, MOP-79551, MOP-115016), and Cancer Research UK (C312/A3726, C312/A6465, C321/A1 1039, C25586/A19540). Secondary analysis of the ITC 4C UK dataset was funded by Cancer Research UK (C25586/A19540) and National Institute for Health Research Public Health Research (13/43/58).

Disclaimer The views and opinions expressed therein are those of the authors and do not necessarily reflect those of the Public Health Research programme, NIHR, NHS or the Department of Health.

Competing interests $A B G, R H, A M$, and TRP are members of the UK Centre for Tobacco \& Alcohol Studies, a UK Clinical Research Collaboration Public Health Research: Centre of Excellence whose work is supported by funding from the Medical Research Council, British Heart Foundation, Cancer Research UK, Economic and Social Research Council and the National Institute for Health Research under the auspices of the UK Clinical Research Collaboration (MR/ K023195/1).

Patient consent Not required.

Ethics approval All waves of the study have received ethical approval from the institutional review board/ research ethics committee at the University of Strathclyde (UK).
Provenance and peer review Not commissioned; externally peer reviewed.

Open access This is an open access article distributed in accordance with the Creative Commons Attribution 4.0 Unported (CC BY 4.0) license, which permits others to copy, redistribute, remix, transform and build upon this work for any purpose, provided the original work is properly cited, a link to the licence is given, and indication of whether changes were made. See: https://creativecommons.org/ licenses/by/4.0/.

(c) Article author(s) (or their employer(s) unless otherwise stated in the text of the article) 2019. All rights reserved. No commercial use is permitted unless otherwise expressly granted.

\section{REFERENCES}

1 Chaloupka FJ, Straif K, Leon ME. Effectiveness of tax and price policies in tobacco control. Tob Control 2011;20:235-8.

2 Hiscock R, Bauld L, Amos A, et al. Socioeconomic status and smoking: a review. Ann N Y Acad Sci 2012;1248:107-23.

3 Lorenc T, Petticrew M, Welch V, et al. What types of interventions generate inequalities? Evidence from systematic reviews. J Epidemiol Community Health 2013;67:190-3.

4 Brown T, Platt S, Amos A. Equity impact of population-level interventions and policies to reduce smoking in adults: a systematic review. Drug Alcohol Depend 2014; 138:7-16.

5 Blecher EH, van Walbeek CP. An international analysis of cigarette affordability. Tob Control 2004;13:339-46.

6 Blecher E. Targeting the affordability of cigarettes: a new benchmark for taxation policy in low-income and-middle-income countries. Tob Control 2010;19:325-30.

7 Blecher E, Ross H, Leon ME. Cigarette affordability in Europe. Tob Control 2013;22:e6

8 Scollo M. The Big Mac index of cigarette affordability. Tob Control 1996;5:69.

9 Guindon GE, Tobin S, Yach D. Trends and affordability of cigarette prices: ample room for tax increases and related health gains. Tob Control 2002;11:35-43.

10 Kan MY. Investigating cigarette affordability in 60 cities using the cigarette price-daily income ratio. Tob Control 2007;16:429-32.

11 Blecher EH, van Walbeek CP. Cigarette affordability trends: an update and some methodological comments. Tob Control 2009;18:167-75.

12 Gilmore AB, Tavakoly B, Taylor G, et al. Understanding tobacco industry pricing strategy and whether it undermines tobacco tax policy: the example of the UK cigarette market. Addiction 2013;108:1317-26.

13 Partos TR, Gilmore AB, Hitchman SC, et al. Availability and use of cheap tobacco in the United Kingdom 2002-2014: Findings From the International Tobacco Control Project. Nicotine Tob Res 2018;20:714-24.

14 Kostova D, Chaloupka FJ, Yurekli A, et al. A cross-country study of cigarette prices and affordability: evidence from the Global Adult Tobacco Survey. Tob Control 2014;23:e3.

15 Wilson N, Young D, Weerasekera D, et al. The importance of tobacco prices to rollyour-own (RYO) smokers (national survey data): higher tax needed on RYO. N Z Med J 2009;122:92-6.

16 Rothwell L, Britton J, Bogdanovica I. The relation between cigarette price and hand-rolling tobacco consumption in the UK: an ecological study. BMJ Open 2015;5:e007697.

17 Husain MJ, Kostova D, Mbulo L, et al. Changes in cigarette prices, affordability, and brand-tier consumption after a tobacco tax increase in Thailand: Evidence from the Global Adult Tobacco Surveys, 2009 and 2011. Prev Med 2017;105S:S4-S9.

18 Guindon GE, Driezen P, Chaloupka FJ, et al. Cigarette tax avoidance and evasion: findings from the International Tobacco Control Policy Evaluation (ITC) Project. Tob Control 2014;23(Suppl 1):i13-i22.

19 Joossens L, Lugo A, La Vecchia C, et al. Illicit cigarettes and hand-rolled tobacco in 18 European countries: a cross-sectional survey. Tob Control 2014;23:e17-23.

20 Nagelhout GE, van den Putte B, Allwright S, et al. Socioeconomic and country variations in cross-border cigarette purchasing as tobacco tax avoidance strategy. Findings from the ITC Europe Surveys. Tob Control 2014;23(Suppl 1):i30-i38.

21 Joossens L, Raw M, Joosens L, et al. The tobacco control scale 2013 in Europe. Brussels, Belgium: Association of European Cancer Leagues (ECL), 2014.

22 Bogdanovica I, Murray R, McNeill A, et al. Cigarette price, affordability and smoking prevalence in the European Union. Addiction 2012;107:188-96.

23 Ash ASH. Analysis of tobacco tax increases in the United Kingdom. http://ash.org.uk/ files/documents/ASH_976.pdf (accessed 8 Aug 2016).

24 Union E. European Union. COUNCIL DIRECTIVE 2010/12/EU of 16 February 2010: amending Directives 92/79/EEC, 92/80/EEC and 95/59/EEC on the structure and rates of excise duty applied on manufactured tobacco and Directive 2008/118/EEC. Official J Eur Union 2010:50:1-7.

25 Overview of tax legislation and rates. HM Revenue \& Customs (2011). 2011 http:// webarchive.nationalarchives.gov.uk/20120207151246/http://www.hmrc.gov.uk/ budget2011/overview.htm (accessed 8 Jun 2017).

26 Fong GT, Cummings KM, Borland R, et al. The conceptual framework of the International Tobacco Control (ITC) Policy Evaluation Project. Tob Control 2006;15(Suppl 3):iii3-iii11. 
27 Thompson ME, Fong GT, Hammond D, et al. Method $s$ of the International Tobacco Control (ITC) Four Country Survey. Tob Control 2006;15(Suppl 3):iii12-iii18.

28 European Commission. Excise Duty Tables (REF 1.015, August 2002; REF 1.017, September 2003; REF 1.019, May 2004; REF 1.021, July 2005; REF 1.023, July 2006; REF 1.025, July 2007; REF 1.027, July 2008; REF 1.029 rev.1, July 2009; REF 1031 rev.1, July 2010; REF 1033 rev.3, July 2011; REF 1035 REV 1, July 2012; REF 1038 rev1, July 2013; REF 1041, July 2014). https://ec.europa.eu/taxation customs/ business/excise-duties-alcohol-tobacco-energy/excise-duties-tobacco/excise-dutiescigarettes_en (Accessed 8 Jun 2017)

29 Campbell R. Consumer Price Inflation: July 2015. [dataset version 3A77-323643 (2015). http://www.ons.gov.uk/ons/rel/cpi/consumer-price-indices/june-2015/index. html

(accessed 23 Jan 2017)

30 Kent-Smith R. Gross domestic product (Ave

rage) per head, at current market prices: SA. [dataset version IHXT, 25 May 2017] 2017 https://www.ons.gov.uk/economy/grossdomesticproductgdp/timeseries/ihxt/ pn2 (accessed 8 Jun 2017).
31 Hagenaars AJM, de Vos K, Zaidi MA. Poverty statistics in the late 1980s: research based on micro-data. Luxembourg: Office for Official Publications of the European Communities, 1994.

32 Bosdriesz JR, Willemsen MC, Stronks K, et al. Socioeconomic inequalities in smoking cessation in 11 European countries from 1987 to 2012. J Epidemio/ Community Health 2015:69:886-92.

33 Hiscock R, Bauld L, Amos A, et al. Smoking and socioeconomic status in England: the rise of the never smoker and the disadvantaged smoker. J Public Health 2012;34:390-6.

34 Caleyachetty A, Lewis S, McNeill A, et al. Struggling to make ends meet: exploring pathways to understand why smokers in financial difficulties are less likely to quit successfully. Eur J Public Health 2012;22(Suppl 1):41-8.

35 Chaloupka FJ, Sweanor D, Warner KE. Differential Taxes for Differential Risks--Toward Reduced Harm from Nicotine-Yielding Products. N Engl J Med 2015:373:594-7.

36 Gov.UK. HM Revenue \& Customs Rates of income tax: 1990-91 to 2017-18. accessed 8 Jun 2017 https://www.gov.uk/government/uploads/system/uploads/attachment_ data/file/625244/Table-a2.pdf 